A psicanálise de crianças é uma situação clínica particular em que a violência psíquica tem um lugar maior. O sintoma da criança, sua não demanda, a implicação dos pais, a atividade do terapeuti situam-se nessa dimensão. O dispositivo da cura organiza os laços c scparaçōes cfetivas e simbólicas entre crianças e pais. O eixo adulto-criança, feito de dependência e de diferenciaçio, estrutura a relação terapéutica. Enfim, o analista, na escuta e elaboração que ele propòe, acolhe os movimen. tos pulsionais da criança. Estes, ligados a sexualidade infantil, têm ressonáncia no sentir e na contratransferencia. A ativação dos processos primários inconscicntes i ampliada em cada protagonista neste contexto particular. Os exemplos clínicos evocados esclarecem esses di. ferentes parâmetros. Duas formas de violência psíquica acompanham assim o trabatho psicanalitico: uma mortifera, repetiliva, e outra separadora, portadora de vida, possibilitundo a simbolizaçio dos conflitos

Separação; dispositivo; violência psiquica; transfcrência; contratransferência

\section{CHILD PSYCHOANALYSIS:} A VIOLENT SITUATION

Child psychoanalysis is a particular clinical situation in which psychic violence has a major place. The child's symptom, his nom demand, the parents' implica. tion, the therapist's activity are silliated at this dimension. The cure organizes the links and the eflective and symbolic separations between pirents and children. The axe adult-child, made out of dependence and differenciati. on, structures the therapeutic relationship. The analyst receives the pulsional movements of the child. Clinical excmplifications dear up the se ditferent axes. Two forms of psychic violence follow the psychoanalyticil work: one is mortiterous, reperitive. and the other leads to separation and life, making conflicts symbolization possible. Separation; psychic violence; transference

\section{A PSICANÁLISE DA CRIANÇA: UMA SITUAÇÃO VIOLENTA}

\author{
Bernard Pechberty \\ Tradução: Inesita Machado
}

\section{ORIGENS}

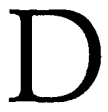

iferentes dimensões da psicanálise da criança colocam a questão da violência psíquica: o lugar dos pais, o desejo da criança, o papel do corpo no engajamento do terapeuta, o contato do analista com pacientes sem linguagem. Essas questões suscitaram, desde a origem, debates que ainda nos esclarecem. A violência própria do inconsciente foi imediatamente sensivel, e os analistas responderam a ela de modo inovador.

Melanie Klein enuncia a primeira das interpretações consideradas como violentas, ou até mesmo traumatizantes. Com o recuo, estas aparecem na medida das patologias encontradas: inibições graves, distúrbios psicóticos e formas autísticas, como demonstra o célebre Caso Dick. Suas intervenções estavam em ressonância com o caos interno da criança, e sua eficácia deve-se a este laço estabelecido com as fantasias precoces. Ela descreve um universo que the foi transmitido pelos pacientes de que cuidava. Suas interpretações referem-se a um imaginário do corpo e das fantasias vividas pela criança. As hipó-

Professor no Departamento de Ciências da Educação, da Universidade de Paris V, psicólogo clínico, psicanalista. 
teses de M. Klein estão de acordo com a experiência infantil em que palavra linguageira e corporal estão misturadas.

O "mundo kleiniano" também fala de uma outra dimensão: a de um real, sentido pelo jovem sujeito, mas que escapa a ele. Este real é aquele de seus movimentos pulsionais, mas também da realidade externa - por exemplo, o fato da sexualidade dos pais. A célebre intervenção "Trem Dick - Estação Mamãe” é exemplar: ela estabelece uma equivalência simbólica estruturante para a criança, mas ela diz respeito também ao encontro de Dick com a sexualidade adulta - ela representa a penetração dos corpos, nomeia algo real (Klein, 1930). A pertinência desta interpretação liga duas realidades pulsionais, a da criança e a do outro.

Se M. Klein trabalha com o mundo interno de seus pacientes, Ferenczi, o primeiro, introduz a questão do ambiente. Ele explicita a relação criança-adulto que atravessa os conflitos identificatórios e reescreve o Édipo freudiano. A relação das mensagens sexuais inconscientes adultas com a vida psíquica da criança torna-se uma questão central. A "confusão das línguas" advém entre a ternura infantil e a paixão adulta (Ferenczi, 1933). A violência nasce deste encontro: vinda do outro, ela é imediatamente interiorizada, nos temos próprios à criança; a libido situa-se a partir daí numa intersubjetividade e numa transmissão. Esta problemática torna-nos sensíveis a uma derivação: a interpretação pode, em alguns casos, aparecer como um forcing terrível do sentido. Assim, pode haver um deslizamento para uma sugestão do terapeuta sobre a criança, se as hipóteses dos praticantes se transformarem numa ideologia fechada. $O$ analista poderá então manter uma violência patológica, sem o saber, por seu modo de intervenção e a manutenção de uma atitude imutável: as terapias não avançam mais.

Este texto será baseado sobre as conseqüências clínicas extraídas de consultas familiares e sobre psicoterapias psicanalíticas conduzidas em instituição e em centros médico-psicopedagógicos. Movimentos psíquicos arcaicos operam em torno do sintoma da criança, entre estas e os adultos, pais e terapeuta. A psicanálise supõe o inconsciente e trabalha com transferências: ao se iniciar, ela bascula a economia psíquica do paciente, de sua família, bem como os valores culturais que dizem respeito ao lugar da criança.

\section{A IMPOTÊNCIA ADULTA}

A emergência do sintoma, corpo estranho, é primeiramente uma violência ao ambiente. Para os pais, vir consultar é responder 
a uma crise que se tornou insuportável. Fracassos escolares, inadaptações, distúrbios da personalidade expressam diferentes sofrimentos, segundo os autores. De acordo com os sintomas, uma criança sentirá vergonha, indiferença ou encontrará prazer em benefício de atenção suplementar. A confusão dos pais é de uma outra natureza, em relação com seu narcisismo e a norma social: o encontro com um terapeuta é uma saída aceita, mas freqüentemente não desejada. Quanto à criança, ela nada pede, pelo menos num primeiro tempo.

As dificuldades da criança focalizam antes de tudo a impotência adulta. A demanda de cuidado é vivida como um fracasso educativo pela família: o sintoma afasta, torna a criança estranha para seus próximos. O recalque da agressividade próprio dessa situação emerge desde as primeiras entrevistas, as recriminações aparecem: "Ele nasceu assim", diz um pai. O sistema de comunicação familiar fica abalado pelo início do tratamento, revelando as raízes intersubjetivas do sintoma. As primeiras entrevistas confirmam um fracasso, uma decepção, e são reveladoras, possibilitam o aparecimento de diversas atitudes: ausência de um dos pais, comportamentos particulares em relação ao sofrimento psíquico da criança, em que a grande solicitude revela seu contrário. Aquilo que é dito com freqüência é muito violento; um dos pais evoca seu não-desejo de criança, diante de seu filho. Com o estabelecimento do tratamento, a impotência dos próximos mostra seu fundo de ódio. Confirma-se uma desilusão, aquela de não se possuir uma criança idģal, imaginária, herdeira do narcisismo dos pais (Freud, 1914).

Esse contexto pesa no tratamento e induz a família a exigências paradoxais: alguns pais querem ajudar a criança confiando-a a um analista, mantendo porém o controle dos processos. A psicanálise de uma criança é acompanhada de múltiplos processos, como ressalta M. Mannoni: estes colorem a relação com o terapeuta como as contra-atitudes deste (Mannoni, 1967). A desconfiança, a transferência negativa em relação ao praticante colocam sob tensão as primeiras entrevistas e são portadoras de ruptura. A ambivalência é regra em todos os protagonistas.

Se freqüentemente a análise se reduz à psicoterapia e à eliminação dos sintomas mais visiveis, é porque os pais não vêem mais utilidade em continuar: eles interrompem então a cura, contrariamente à opinião do terapeuta e da criança. Se esta ambivalência parental não é suficientemente trabalhada, a criança torna-se refém e desinveste o tratamento. Como poderia ela continuar um trabalho psíquico condenado por seus próximos? Dominação, sedução, ódio reatualizam-se em torno dela, que, por seu sintoma, decepciona o ideal familiar.

Instala-se um laço complexo, a exigência social prescreve um tratamento, a criança nada pede e a implicação dos pais é, de início, nula ou ambígua. Isto coloca a questão de sua acolhida e de sua presença. Desde o início da psicanálise da criança, os terapeutas mantiveram posições antagônicas sobre esse ponto: A. 
Freud colocava-se voluntariamente numa posição de educadora; $M$. Klein afastava os pais da cura; F. Dolto, ao contrário, exigia a vinda e o dizer parental no início de uma terapia. As diferentes atitudes clínicas em relação à família refletem concepções teóricas e fantasmáticas, divergentes por parte dos terapeutas.

Com freqüência, a cura é prescrita pela escola ou por um médico: A proposta de terapia constitui então uma violência para os pais. A implicação familiar deve ser constituida pelos terapeutas.

"Pierre, 10 anos, tem pesadelos; sua mãe o acompanha apesar da hostilidade do pai ao tratamento: 'Ele não é um intelectual', diz a mãe para desculpá-lo. Na sessão, Pierre não pára de falar no pai, indicando seu valor protetor. Este é esportista, e seu filho identifica-se com ele. Um dia o pai irromperá vivamente, intimando o terapeuta a 'dizer-lhe tudo'. Uma entrevista the é proposta na semana seguinte, à qual ele não comparece."

Essa manifestação de angústia do pai corresponde à violência sentida pelo fato de comprometer-se pessoalmente com um tratamento sem tê-lo desejado. Além da rivalidade com um outro homem, o terapeuta, que se supõe ter mais êxito do que ele, o pai descobre que a cura the escapa, e, mais do que isso, escapa-lhe a vida psíquica de seu filho.

Certas posições familiares emergem: ataque ao quadro, críticas do terapeuta, tentativas de colocar os terapeutas uns contra os outros. Os pais estão intimamente implicados pelo trabalho que está em jogo. As 
ausências, os esquecimentos das consultas da criança são também expressōes da rejeição implícita na terapia.

Em certas patologias atuais, como as violências sexuais ou incestuosas, o fracasso das prescriçōes psicoterapêtuticas para uma criança vítima de um dos pais é significativo desses paradoxos.

"François, 12 anos, vem à terapia; seu pai foi julgado e condenado por abusos sexuais sobre seus filhos, e particularmente, sobre a irmã de François. Esta foi colocada numa outra família. Após o cumprimento da pena, as condutas familiares tornaram-se aparentemente normais. Os pais foram obrigados a se cuidar e a fazer consultas. Na sessão, François desenha homens com corpos fascinantes, heróis de histórias em quadrinhos. Durantes alguns encontros, ele recusará a terapia, acusando sua irmã de sedução, negando qualquer responsabilidade paterna. Muito rapidamente ele decidirá não voltar mais."

O conflito das imagens parentais internas, as decisões judicrais, o cuidado misturam-se para François. A confusão social e psíquica atinge seu ponto máximo. Como poderia ele iniciar um tratamento, quando a elaboração do traumatismo sofrido supõe a acusação dos pais, autores de abusos, mas também seres amados? Como pode seu sofrimento aparecer-lhe como um sintoma, objeto de cuidado, quando as diferentes formas de violência adulta, internas e externas, são confundidas nesse ponto? À beira da adolescência, François estreita suas identificações protetoras, incapaz no momento de aceitar o conflito interno.

O que também é violência é a indicação do tratamento concebido como produto aplicável a diferentes sujeitos. A injunção terapêutica, assimilada aqui a uma prescrição médica ou a um medicamento, é asseguradora num primeiro tempo; os processos psíquicos mobilizados fundam ao contrário uma dinâmica que implica os atores e as posições de modo diverso do retiro ou da des-responsabilização. A família, a instituição, a criança encontram-se então modificados por essas determinantes. Nesses locais de tratamento, a psicoterapia é às vezes colocada assim, como um produto, não considerando a experiência da criança: os mais sãos restabelecem então uma boa medida.

"Victor apresenta problemas de inibição e de elocução: após ter feito, durante muito tempo, tratamento psicomotor e fonoalldiológico, apresenta dificuldades escolares. Em reuniões de equipe, diz-se que 'só the falta uma coisa', isto é, uma psicoterapia. Em sua única consulta, Victor dirá ao terapeuta que ele agora quer "ser normal', isto é, não vir mais ao Centro após todos esses anos."

Essa transformação da indicação de psicoterapia para uma consulta possibilitou a essa criança fechar seu trajeto de tratado. Esta 
situação indica a contratransferência dos terapeutas e uma derivação institucional possível. Pais, atendentes manifestam atitudes superprotetoras que se tornam dominação. Aqui a violência tem origem no grupo atendente que nega a evolução da criança, fora de seu controle.

Esses processos mostram duas faces da violência: uma, sofrida, negando o conflito psíquico, repetitiva, e outra, viva, simbolizante.

\section{TERAPIA, UM DISPOSITIVO SEPARADOR}

Uma outra dimensão simbolizada é a da separação. De fato, se o projeto analítico é conhecido, insiste-se menos sobre os efeitos do dispositivo da cura e de seu quadro. O tratamento institui uma nova separação, violenta, entre a criança e sua família (Pechberty, 1985). Esta distingue-se das experiências anteriores: nascimento do corpo materno, distanciamento da família, socialização pelo grupo dos pares, na escola. O tratamento isola o jovem paciente de seus pais, regularmente e por longo tempo: ela cria uma comunicação em que o íntimo de uma criança diz-se, a um adulto, devotado em ficar fora da família.

$O$ tratamento introduz diversas modalidades de troca entre adultos e terapeuta. O espaço terapêutico traz em si conflitos possíveis: entre a dependência da criança de seus pais e a liberdade encorajada durante as sessões. Mais radicalmente, os adultos vêem-se confrontados à presença do inconsciente em seu filho, e neles mesmos. Os conflitos interiorizam-se: os pais são questionados subjetivamente e em seus laços conjugais, diante de seu filho tornado paciente. Aqui se fundem alguns fenômenos: atitudes parentais singulares com relação à psicoterapia, mal aceita, confundida durante meses, com "cursos", fantasias na relação criança-terapeuta, passagens ao ato que interrompem brutalmente o tratamento quando os sintomas começam a desaparecer.

A violência psíquica que circula deve ser decifrada: esta fabricou o sintoma e condensa elementos da história coletiva e pessoal. Os primeiros encontros são fundamentais e dividem os papéis de outro modo. São às vezes imediatamente terapêuticos: o tratamento funciona então como um rito de passagem, dando um novo lugar à criança.

"Hassan, 7 anos, menino apagado, tem enurese durante anos; os pais, de origem marroquina, vêm falar, cada um de seu lado. A mãe lembra-se e expressa o tempo de sua juventude, de sua adolescência, 'de antes que a casassem' com este homem, a quem ela é no entanto apegada. Há dois anos o pai parte, sozinho com os 
filhos, durante as férias, para a terra de origem. Ele sabe de sua desunião conjugal, ele não compreende. Não é necessário ir mais longe: paralelamente às consultas de seus pais, Hassan deixa de ser enurético, faz grandes progressos escolares, adota condutas mais viris. O trabalho psicoterápico começa então para ele."

A vinda ao centro de tratamento funcionou aqui como um sinal de reconhecimento cultural e pessoal: o direito de cuidar, o que é dito nas entrevistas modificou o sistema de comunicação do casal e da família. Um corte simbólico delimitou as experiências de outra maneira, o antes e o depois de uma história comum. As dificuldades de Hassan inscreviam em seu corpo e em suas relações com os outros uma infância mal simbolizada. O sintoma era o eco de seus sofrimentos familiares, em que estava em jogo uma parte de sua identidade. A violência sentida pode se transformar num conflito histórico portador de sentido.

O dispositivo da cura pode, muito rapidamente, entrar em ressonância com o traço daquilo que fez traumatismo: o analista deve então manter toda sua liberdade no seu modo de trabalhar. Ferenczi ressaltou o papel traumatogennico do quadro (Ferenczi, 1932): o tratamento pode manter a repetição, e não a mudança, se o terapeuta não estiver sustentado por um desejo vivo e comprometido. Desse modo, o manejo das primeiras entrevistas revela processos que operam entre vários espaços, externo e interno, entre a situação familiar e o aparelho psíquico da criança. 
"Sonia, 5 anos, menininha portuguesa, vem à terapia por problemas de inibição, de mutismo e de grande dependência de sua mãe; aliás, ela se recusa a deixá-la durante as sessões. Ora, encontra-se no primeiro plano das entrevistas uma experiência traumática de separação precoce, a que viveu essa menininha quando seus pais partiram para a França, deixando-a com os avós durante um ano."

"Sonia nunca fala ao analista, exprime-se por meio de mímicas. Ela desenha, sempre em silêncio, um mar, uma costa, depois uma grande senhora vestida,com um vestido vermelho, com uma pulseira de motivos complicados. Pouco a pouco, Sonia confirma tratar-se de sua mãe, na época em que esta veio buscá-la em Portugal. Esta, presente, diz então, perturbada, que realmente ela usava este vestido e estas bijuterias, tais como sua filha os desenha. Durante várias sessões falaremos em torno deste acontecimento. No exterior, ao mesmo tempo, as condutas de retraimento evoluem, os sintomas motivo da consulta desaparecem e, a partir daí, Sonia aceita vir sozinha."

Vê-se de que modo uma parte do traumatismo é representada nos sintomas: mutismo e retraimento repetem na cura experiências vividas antes, quando do afastamento familiar. Essas atitudes representam o passado, quase que diretamente, na apresentação transferencial de Sonia. As primeiras entrevistas com a menininha sozinha reativam a situação inicial de separação, desta vez com a possibilidade de opor-se a ela ativamente. Vindo à consulta com sua mãe, ela introduz as condições psíquicas que lhe permitem elaborar uma parte esquecida de sua história.

Se o terapeuta tivesse insistido em ficar sozinho com Sonia, a situação teria repetido sem fim o traumatismo. A presença da mãe foi determinante, possibilitou a junção da fantasia e de sua simbolização. Assim, a dimensão traumática do dispositivo e da atitude terapêtica tem aqui efeitos clínicos importantes. Este distanciamento controlado tem ressonância com outras separações mais simbólicas que o terapeuta deverá considerar. Sem dúvida algumas estruturas de personalidade são imediatamente sensíveis a esta dimensão.

Assim, o dispositivo psicoterapêutico tem uma função separadora. O tratamento isola a criança de seus pais e remodela as relações com os adultos. Mobilizando transferências, ela reativa acontecimentos que marcaram a história. Assim ela leva a processos psíquicos em que a criança pode se separar de algumas fantasias, abandonar modos de gozo para avançar. A violência designa portanto diferentes planos: os efeitos de ressonância do inconsciente nos pais, a arbitrariedade de um tratamento sempre semelhante e como que colado, e finalmente a dimensão do trauma.

\section{ESTRANHAMENTO CULTURAL}

A extensão da análise para a criança também tem efeitos sobre as representações sociais desta. Este pon- 
to, relativamente negligenciado, dá um sentido particular às relações terapêuticas que se instalam. Os projetos e as regras que fundam o tratamento são dissonantes com certos valores culturais: o "segredo" das sessões, a regra de livre associação, a atitude analítica parecem estranhas ou angustiantes para os que estão à sua volta, e opõem-se à exigência ideológica de um laço educativo transparente e fraterno, entre adultos e crianças, próprio da nossa modernidade. A afirmação de uma vida psíquica da criança, a confidencialidade da situação terapêutica, a suspensão da influência paterna rompem com o ideal de uma comunicação igualitária e são mal percebidos. O código e os valores do campo terapêutico são fontes de incômodo.

Nas instituições em que trabalham os psicanalistas de crianças, observa-se a dificuldade de certos pais em se posicionar. O relativo silêncio do terapeuta, condição da confiança da criança, inquieta. A sociedade, por meio da escola ou do médico, prescreveu uma terapia, a exigência de adaptação funciona, mas aparecem outras questões: o pagamento do tratamento leva alguns pais a uma atitude em que o tratamento é percebido como algo devido. O terapeuta deveria devolver-lhes alguma coisa, para estes que the confiaram seu filho: um resultado rápido e tangivel, avaliações. Assim as condutas reivindicativas manifestam-se desde o início do tratamento.

A entrada na psicoterapia confirma uma estigmatização social e muitos pais estabelecem laços difíceis com o terapeuta. As imagens projetadas sobre ele são índices transferenciais, mas expressam também os cenários culturais e fantasmáticos específicos; o analista é colocado no lugar de um cirurgião - "Retire o mal de nosso filho e devolva-nos em perfeito estado, como antes" -, de intérprete "Você que sabe, tente fazê-lo compreender que..." - ou de educador todo-poderoso delegado pela sociedade.

\section{VIOLÊNCIAS DURANTE A CURA}

\section{A) Jean}

"Jean, 8 anos, dá a impressão de estar ao lado, fora; ele esquece suas coisas, não brinca com as outras crianças, e o diálogo é quase impossivel. Durante as primeiras entrevistas, sua mãe diz que não o queria, e o pai apresenta intervenções educativas contraditórias. Os pais, religiosos, exercem grande domínio sobre o filho. Quando seus resultados escolares baixam enormemente, eles o matriculam numa escola religiosa, rejeitada pela criança.” 
"No tratamento, Jean encena seu retraimento, seu mutismo. Demonstra comportamentos paradoxais, desenha letras para papai e mamãe, mensagens afogadas depois em mamadeiras. Faz jogos intermináveis diante do espelho, coloca-se no lugar de uma mãe que protege seu bebê de agressões estranhas."

"O terapeuta raramente é solicitado. O retraimento de Jean é rompido por breves momentos de autêntica comunicação e aparece então uma maciça angústia: ele conta seus pesadelos, sua sensação de não ter os olhos no lugar, cenas de abandono pelos adultos, à noite. Mede-se então a violência da defesa, avesso da pulsão. A angústia emerge numa relação: o terapeuta a sustenta antes que a criança possa assumi-la sozinha. Esta angústia, afeto de base desqualificado (Laplanche, 1971), ligada ao enigma do desejo do outro (Lacan, 1962) evoca experiências primárias, é o signo de situações precoces em que não havia ninguém para estar em ligação com o bebê."

"Jean, em seus jogos com o espelho, ataca, protege. Expressa pulsões, domestica-as falando e brincando. A terapia serve-lhe como continente para que ele elabore e viva, talvez 'pela primeira vez' (Winnicott, 1958), um traumatismo, para que um recalque primário se estabeleça."

"A violência também estava presente em torno do tratamento, e o mal-estar familiar aparecia. A terapia de Jean foi muito maltratada por seus pais: eles atacavam verbalmente os terapeutas (médico e terapeuta), tentavam cindi-los, querendo utilizar o terapeuta como substituto paterno eficaz. O pai nega a doença do filho, recriminando o terapeuta por não se situar num plano educativo. Seria necessário portanto proteger o trabalho, sustentar essas transferências negativas, condição para que o trabalho prossiga."

Com freqüência irritei-me por não compreender Jean. Assim, por um tempo insisti em que ele respondesse às minhas perguntas, entrando por aí na tentação educativa - como o pai. Ao mesmo tempo, eu falava muito com ele, um pouco demais, mas minhas palavras tinham sobretudo uma função de garantia diante do caos do mundo da criança. Somente quando não me incomodei mais com esta comunicação incompreensível que Jean ocupou um outro lugar, ao mesmo tempo simbólico e real. Ele então me solicitou para exprimir algumas angústias. Mais tarde, ele me acusou de ser uma "boca costurada".

De fato eu queria fazer violência ao funcionamento de Jean para fazê-lo entrar num diálogo coerente, maduro, que asseguraria a todos e primeiramente a mim, seu terapeuta. Minhas questões visavam estabelecer um sentido pelo diálogo, transformando-se em injunção educativa. Minha angústia era a da distância muito grande em relação a esta criança. Como terapeuta, não estaria me identifi- 


\section{Dossiê}

cando com um pai melhor, como se o êxito terapêutico pudesse substituir o fracasso educativo? Essas observações possibilitam identificar melhor as contra-violências educativas que se alimentam da angústia de não compreender, diante da desorganização psíquica.

B) Fabien

"Fabien, 6 anos, apresenta uma grave desarmonia: ele se apresenta como uma criança imatura, com voz de matraca; ele está adaptado para o mínimo social, mas de fato está separado dos outros, em sua bolha, muito sozinho. Está fora da relação, numa comunicação incompreensível."

"Jogos com água solitários, histórias contadas para si mesmo, Fabien está em seu mundo. Ele lava os objetos, as paredes e repete as mesmas brincadeiras. Com freqüência eu interpretava seu medo, seu ódio, sua angústia, em relação a imagens internas insuportáveis. Nada tem efeito, as palavras do adulto estão dissociadas da sua experiência, não a atingem, nada mudam em seu funcionamento: Fabien está fora. Um dia, intervenho para interromper esta lavagem, arranco a esponja das mãos de Fabien, provocando então fortes reações agressivas. A criança quer retomar o objeto: cólera, corpo-a-corpo violento com o terapeuta produzem-se então."

"Com esta criança, a primeira questão foi encontrar o contato, à imagem dos tratamentos de crianças autistas (Tustin, 1986). O tratamento demonstra outra coisa: este encontro se passa fora da palavra interpretante. Ele engloba o corpo do terapeuta, sua presença simbólica, mas também efetiva, corporal. A intervenção do 
analista é aqui um ato, a marca da alteridade no tratamento."

"Fabien também brinca de telefonar, sozinho diante de mim. O que ele exprime do longínquo, de sua impossibilidade de comunicar com esta chamada encenada? Ele murmura e responde então numa língua estranha. Eu tomo o partido de forçar a comunicação, de entrar em seu jogo e dizer 'alô? alô?' Fabien me olha então estupefato e cheio de angústia. A atividade vai parar, a relação está à beira da mudança."

Nessa observação, o ato do terapeuta é uma intervenção, e não uma interpretação dita. O comprometimento do terapeuta cria um lugar vazio para um objeto de troca que esteja ligado ao outro. Esta iniciativa violenta a respeito da esponja possibilitou a comunicação com Fabien, com as representações das pulsões de vida da criança, além das condutas repetitivas fixas.

A mudança terapêutica passou por um confronto. O terapeuta interveio fisicamente, numa relação com o corpo significante para a criança; esta presença real do terapeuta possibilitou a modificação do discurso. Estabeleceu-se uma relação em torno do objeto faltante que adquiriu um valor simbólico: Fabien sentiu um novo tipo de angústia, do lado da vida. Produziu-se uma abertura em seu mundo fechado, aconteceu um encontro. Os desejos dos protagonistas eram diferentes: no adulto, terapêtico e separador, na criança, fechado sobre si; estes se ligaram às pulsões, constituindo um conflito interno possível para Fabien. Um novo equilíbrio entre pul- 
sões de vida e pulsões de morte opera-se sem dúvida.

\section{UMA SITUAÇÃO COMPLEXA}

Do exterior para o interior $\mathrm{da}$ cura, a violência psíquica exprime-se assim de diferentes modos. Vimos de que maneira os pais poderiam interromper o tratamento quando os sintomas da criança começavam a desaparecer. O fato de que este retome sua evolução psíquica fora de seu controle pode revelar-se insustentável.

"Isabelle, 8 anos, é inibida em suas relações sociais, embaraçada, e enfrenta um fracasso escolar. Após alguns meses a situação melhora, até na escola. Neste mesmo período a menina produz, em terapia, uma série de desenhos: estes representam uma menininha móvel, dançante, feliz e testemunham a imagem de um corpo novo, narcísico, em construção. A mãe interrompe o tratamento, sem aviso: ela não suporta a autonomia de sua filha."

As passagens ao ato $e$ as resistências paternas ao tratamento às vezes tomam a forma do sintoma.

"Marc, 6 anos, sofre de ausências epiléticas. Após uma fase de desconfiança e de rejeição, ele pode confiar no terapeuta. A resistência à psicoterapia vem da família e também terá a forma de ausências: Marc se ausenta, seus pais não cumprem com os horários das consultas, o terapeuta deve pedir novamente a presença regular da criança. Aqui também a fa- mília não reconhece a dimensão psíquica: aparentemente aceita, a psicoterapia é de fato recusada. Os pais, 'esquecendo' de levar seu filho às sessões, transformam o tratamento em consultas do tipo médicas, retomando o poder sobre o dispositivo e o terapeuta. A sensação de ser excluído dos processos de mudança de seu filho, mobilizados por um outro adulto, causou esta interrupção.”

Quanto ao analista, uma outra violência pode infiltrar sua intervenção, sem que ele perceba, e fechar definitivamente a comunicação: esta pode tomar dois aspectos, o cuidado prolongado ou a tentação educativa. O trabalho com a criança, pela multiplicidade das transferências que o atravessa - a dos pais, a da criança e a do terapeuta -, leva o analista a essas duas vertentes. Tratar de uma criança em dificuldade revela sua própria experiência infantil e reativa nele uma identificação de pai idealizada ou reparadora. Sua transferência de analista anima as fantasias específicas na condução do tratamento: anular a família do paciente, fazer nascer uma nova criança maravilhosa graças ao tratamento, reeducá-la. Reparar, tratar, educar são dimensões mobilizadas no trabalho com a criança. Resulta daí um certo tipo de imaginário: este está sem dúvida ligado à experiência paterna, específica do mundo adulto. O processo de humanização da criança é iniciático e educativo: vem acompanhado de identificações mútuas entre adulto e criança. Durante seu crescimento, este se constrói a partir daquilo que ele recebe e se apropria de seus ascendentes. Este ato é implicitamen- 
te mobilizado no trabalho clínico com a criança.

Todos esses parâmetros induzem a uma situação complexa. Várias perspectivas esclarecem então a natureza da violência psíquica no trabatho com o paciente, o analista e na própria situação terapêutica.

\section{A) A criança}

Para a criança as consultas servem de amplificador: a permissividade dada à expressão dos fantasmas ativa a expressão pulsional. A transferência com o adulto terapeuta, que encoraja e reconhece todas as formas de sua atividade, mobiliza os conflitos internos. O tratamento irá favorecer para a criança uma vivência poderosa alimentada pelo sentimento de ter apenas para si o terapeuta; esta experiência vai rapidamente de encontro à não resposta do analista. À excitação sucede a agressividade. A transferência infantil serve como câmara de eco aos conflitos identificatórios que levaram ao sintoma. A angústia é a marca da mobilização psíquica, e este sentimento novo, em relação a um outro, gera violência.

Alguns traços especificam a transferência infantil: o sentimento do jovem paciente de estar dividido entre os adultos - família e terapeuta - indica a agressividade, a clivagem da transferência e a desconfiança. A regularidade das sessões, como vimos, separa a criança de seus próximos e a obriga a contar suas intimidades ao terapeuta, posto assim em posição de perseguidor. A escuta analítica remete ao sujeito da violência latente de sua expressão agressiva. O desejo da criança de parar o tratamento em seu início, com freqüên- 
cia, está ligado ao medo dessa violência interna. Além disso, a educação paterna obriga particularmente ao recalque das pulsões hostis. Isto reforça nas crianças neuróticas a força dos desejos de morte edípicos, impossiveis de serem ditos em família; vão inicialmente se manifestar por uma transferência negativa dirigida ao terapeuta.

Com as psicoses e as inibições graves, $M$. Klein foi a primeira a valorizar o caráter destruidor das pulsões que se volta contra a identidade dos sujeitos: a intrincação da pulsão de morte com a libido alimenta então a transferência infantil. M. Klein também ressaltou a rapidez do ritmo de expressão das fantasias infantis, na sessão: estes acompanham as atividades do paciente e a resistência se dá pela passagem de um registro de expressão a outro, do desenho do jogo ou ação. Assim o avanço terapêutico da criança, a necessidade de enfrentar seus conflitos e de ter que abandonar gozos regressivos mobilizam as pulsões parciais, colocando à prova a unidade do eu. As identificações edípicas com freqüência estão próximas da gênese do eu num jovem paciente: isto pode explicar o conselho dado por Winnicott aos terapeutas, de respeitar esta fragilidade do eu, particularmente nas crianças em período de latência. Com o tratamento, as pulsões recompõem-se numa nova organização libidinal. Esta evolução facilita a maturação e induz a mecanismos de defesa violentos, na medida das mudanças mobilizadas. Os pais constatam assim com freqüência uma nova liberdade de seus filhos, um recuo das inibi- ções que vem acompanhado de uma expressão maior de sua agressividade.

B) $\mathrm{O}$ analista

A realidade psíquica infantil e o contexto da cura induzem a transferências e a afetos específicos nos analistas. Manter seu lugar de analista é uma aposta, pois os paradoxos se multiplicam: ele deve se deslocar das posições parentais. $O$ encontro com uma criança que não pediu para vir o induz a se impor, a forçar a transferência. O terapeuta solicita, mantém o tratamento e seu sentido. A partir daí, ele trabalha também com sua contratransferência, e este é acompanhado por intervenções: ele pode desejar afastar os pais para ter mais exito do que eles, ou querer apoiar-se sobre sua presença quando o tratamento é muito difícil. Os fantasmas educativos, parentais ou reparadores, fazem pressão sobre ele. O analista é tão mais sensível a estas quanto se inscreve nas transferências familiares mobilizadas pelo tratamento. Esta situação obriga a uma permanente vigilância sobre os efeitos de sua atividade.

Enfim, reconhecer o desejo da criança, nomeá-lo, supõe uma identifícação com seus conflitos psíquicos. $O$ analista encontra então como um golpe a presença da sexualidade infantil; ser terapeuta é também receber e metabolizar esses movimentos libidinais. Essas intervenções recebem e orientam a expressão das pulsões, na sessão. A contratransferência pode também indicar a confusão dos registros: por exemplo, uma excessiva proximidade com a problemática do sujeito, experimentada numa vivência fusional ou muito distante. 
Encontra-se uma outra particularidade: F. Dolto ressaltava que o Édipo, despertado no tratamento, deve se sentir nos pais reais da criança, tais como eles são (Dolto, 1982). Querer substituí-los é um fantasma possível do analista, que pode levar a um desvio perverso. Essas observações demonstram o lugar paradoxal do terapeuta: ser o destinatário de transferências, mas aceitar imediatamente assegurar a transição.

"Jim, 11 anos, é uma criança inteligente, hipercinética, ansiosa, que manipula objetos e pessoas e falando sem parar. Tem um pensamento mágico em que tudo deve se realizar imediatamente. Essa excitação patológica encontra suas raízes nas carências educativas antigas. Durante vários anos, Jim não encontrava obstáculos a seus desejos. O pai, particularmente, não the punha limites; consciente deste erro, ele começa a fazê-lo, mas Jim consegue criar tensão tão bem, que os golpes caem com muita violência. Recentemente, o casal quase se separou."

"O tratamento inscrevia-se nesse contexto. $\mathrm{O}$ analista também assumiu esta excitação permanente, na sessão e no Centro. Quando a família modificou suas atitudes educativas, Jim quis parar o tratamento; o terapeuta, tido como amigo e aliado, tornou-se um inimigo que deveria desaparecer de seu campo. A mutação de Jim, encontrando uma lei e seu pai de outro modo, foi acompanhada de uma provocação incessante dirigida ao analista: injúrias, múltiplas condutas transgressivas. Este decidiu manter as sessões por um tempo para não satisfazer de novo ao desejo todo-poderoso da criança e dar um sentido à transferência negativa."

O súbito aparecimento da raiva e da violência de Jim, na transferência, acompanha esta nova presença paterna, interditadora. Opera-se uma clivagem: o terapeuta representa agora a face imaginária e má de um pai que de agora em diante se faz realmente respeitar. Estabelece-se um jogo entre o contexto familiar mais calmo e o analista: a criança expressa com ele uma posição infantil dominante, que está sendo ultrapassada. A violência é ao mesmo tempo um resto de passado arcaico e o sinal de que Jim deve se dirigir não mais ao terapeuta, tido como responsável por esta nova situação, mas a um pai.

Esta observação confirma que o analista recebe uma transferência da qual uma parte deve voltar aos pais. Os movimentos psíquicos do paciente, despertados no tratamento, com freqüência permanecem não interpretáveis, sob o risco de se tomar uma posição parental ou educativa. Esta obrigação de ouvir, sem necessariamente intervir, é também uma violência ao analista; a situação reforça o efeito das pulsões e o questiona em sua própria dinâmica infantil. A originalidade do contexto clínico, o estabelecimento do 
olhar e da sensorialidade no encontro com a criança acentuam esta dimensão.

A dimensão da sedução original designa o enigma das mensagens sexuais inconscientes adultas às quais a criança é confrontada (Laplanche, 1989). Talvez esta seja uma das razões da especificidade do tratamento da criança. De fato, a mistura de dependência, de expressão pulsional e de poder imaginário da criança exerce um fascínio sobre o adulto e a contratransferência em relação a ele varia segundo o sexo, a idade a as estruturas clínicas dos pacientes.

As excitações transmitidas ao terapeuta provêm da vida pulsional do paciente. $\mathrm{O}$ analista trabalha com o que sente na transferência, e sublinhar tal elemento o remete à sua própria dimensão infantil. Suas intervenções têm ressonância com a energia e os significantes pulsionais da criança que ele the devolve, sob forma de questionamento.

A pulsão, escrevia Freud, não é inteiramente educável. Aqui, são as pulsões parciais que estão mobilizadas atrás dos conflitos identificatórios e a expressão dos desejos. Os movimentos edípicos infantis são igualmente ativos, e trabalham-se por alusão. Encontra-se aqui uma questão essencial levantada por vários analistas: o risco da interpretação sistemática. Winnicott ressalta que esta não deve ser um saber todo-poderoso, dita com as palavras do adulto: é ainda a "violência" da intervenção kleiniana que é visada. A obra kleiniana tem de fato desencadeado reações apaixonadas pela brutalidade de suas interpretações. No entanto, estas não 
gostariam de dar palavra à virulência das pulsões despertadas no tratamento, particularmente à sexualidade infantil mais arcaica? A verdadeira questão é não fechar o questionamento por uma atitude interpretadora que encerra, e finalmente defensiva. Os fantasmas descritos por $M$. Klein ligam-se às indicações dadas por Freud sobre a amoralidade dada às pulsões. Para ela, o Édipo e a castração, elementos estruturantes do psiquismo, estão presentes, enquanto fantasmas, desde o início; a cura vai facilitar sua elaboração. A dificuldade do trabalho do analista é a de reconhecer $\mathrm{e}$ interpretar esses elementos fundadores, sem adotar uma posição de saber e de mestria.

\section{CRIANÇA, OBJETO OU SUJEITO?}

Winnicott compara a transferência de certos adultos psicóticos com as primeiras relações de um recém-nascido. Seu tratamento, escreve ele, institui uma experiência nova, a de uma "primeira vez", em que um paciente pode, por exemplo, expressar finalmente cólera. Toda análise inclui esta dimensão de "primeira vez", de "primeiro encontro", entre si e o outro. Do mesmo modo, aquilo que é novo para a criança é a experiência da transferência e do modo de resposta que o terapeuta lhe dirige: ela pode então expressar de outro modo seu gozo infantil, sem afastá-lo para crescer.

Nas análises, o eixo da relação adulto-criança organiza a expressão do inconsciente. As pulsões manifestam-se de formas variadas, fantasias, palavras e condutas diversas - excitação, retraimento, ganchos. Qual será a resposta do terapeuta? Sua contratransferência é fortemente solicitada, fazendo eco com sua própria experiência infantil. As observações de Jean e de Fabien, próximas à psicose, demonstram como eles ocupavam um lugar de objeto no desejo do outro, reproduzindo indefinidamente as mesmas atitudes, e evitando qualquer contato novo com o exterior. Com as psicoses de forma autista, a presença do outro é negada. Por sua intervenção, o terapeuta faz violência ao mundo fechado da criança: ele se introduz e se impõe como parceiro. Ele representa as pulsões de vida para um paciente levado às condutas repetitivas e à morte psíquica.

Toda mudança pode ser acompanhada por uma regressão: certas crianças induzem uma relação fusional, erotizada, que inclui o terapeuta em seu movimento. $O$ analista se presta a isso, mas sua atividade simbolizante é prova de uma violência separadora. Sustentando a situação terapêtica e seu enquadre, ele introduz uma distância que permite à criança afastar-se de sua violência pulsional interna, deslocá-la. A relação terapêtica pode então interiorizar-se, e a criança pode estruturar-se de outro modo.

C) $\mathrm{O}$ encontro terapêutico

Assim, o encontro terapêutico é sempre precário. Encontramos questionamentos abertos no início desse texto: indo da periferia ao núcleo da situação analítica, mostram-se vários níveis de violência. A relação 
adulto-criança é solicitada, em vários níveis, pelo tratamento; se seguirmos as idéias de Ferenczi, a dificuldade do tratamento pode ser descrita em termos de "confusão de línguas". O colóquio terapêutico reativa conflitos psíquicos de base, pois recoloca em jogo a transmissão original do desejo de viver, entre o adulto e a criança; esta situação mobiliza as figuras da sedução original entre os dois protagonistas, até a reativação da sexualidade infantil no terapeuta.

Por meio de sua transferência, a criança projeta no analista imagens parentais, mas também representações ideais do adulto que ele poderia se tornar. Repetem-se conflitos e fantasias, mas no quadro de uma nova experiência, a de um primeiro encontro com um terapeuta, adulto. Esta relação é efetiva, mas também mítica, ideal, abrindo a questão do desejo de crescer. O tratamento torna-se um lugar de projeção do passado, de fantasias sobre um futuro possível, idealizado ou malevolente. Distúrbios neuróticos e psicoses também solicitam o terapeuta no eco de sua história: cuidar, tratar uma criança aproxima-o de sua dimensão infantil. Um processo sutil amarra-se entre as identificações ideais que virão da criança, e a ressonância inconsciente do tratamento no adulto. Pai faltante, imagem de uma mãe misturada, ou figura homossexual do duplo são exemplos de projeções operadas pela criança sobre o terapeuta. Este é chamado a ocupar lugares imaginários na transferência, a entendê-los e até mesmo a pô-los em palavras: ele manifesta a seu paciente como ele pode sustentar a abertura do inconsciente, 
nele e para o outro, mantendo seus próprios recalques e uma posição de "adulto". Ferenczi mostrou igualmente, em seu tempo, como a criança persiste no analista adulto. Seus esforços técnicos ilustram essa insatisfação e sua busca de uma outra definição da situação analítica.

Assim, a criança reproduz seu lugar de objeto para seus pais na cura, mas também seu possível desapego (Lacan, 1969). Esta tensão a leva a formular questões que em parte permanecerão sem resposta, pois dizem respeito ao interdito, fundador de seu desejo. Com o tratamento, ela desenvolve sua problemática e a modifica. Ela toma o analista ao pé da letra pelo modo com que este a ouve e responde a ela. Ela solicita o inconsciente do terapeuta, levandoo a intervir de modo protetor ou regressivo. Se este é sensível a esses processos infantis sem se confundir com eles, a violência traumática sofrida pela criança pode se transformar em abertura terapêutica e em criação. Assim, esta dimensão traumática manifesta igualmente seu aspecto evolutivo possível.

A violência pulsional atravessa portanto necessariamente o encontro terapêutico. Objeto perdido, excitações, restos de gozos atualizam-se aí. Sublinhemos ainda os paradoxos que organizam o tratamento da criança: a não-demanda do paciente obriga o terapeuta a suscitar o interesse pela cura, a sustentar um quadro e um projeto, a romper com as atitudes habituais. A oferta de transferência e o laço com a criança e com sua família fazem ressurgir no analista elementos infantis a partir dos quais ele intervirá: vimos o quanto sua contratransferência era solicitada, como pai ou como educador na cura. A vigilância em relação às transferências em jogo, a necessidade de inventar, muito sensível em analistas de crianças, fazem violência aos hábitos e às regras estabelecidas no campo analítico (Pechberty, 2000).

O tratamento apresenta uma ambigüidade fundadora: ela faz encontrarem-se uma criança e um adulto, figura estranha, lugar de projeção. O analista, profissional autorizado pelos pais e pela sociedade para o bem da criança, não propõe nada de tangível. Numa posição instável entre o Ideal do Eu e o Eu Ideal, ele vai ocupar os lugares devolvidos pela transferência de seu paciente. Por outro lado, ele pode imaginar encontrar naquilo que ele sente a criança que ele foi ou que ele poderia ter sido. Suas intervenções o ultrapassam em parte e a cura navega num paradoxo constante.

\section{PSICANALIZAR UMA CRIANÇA É PORTANTO UMA TAREFA IMPOSSÍVEL?}

O tratamento, suspendendo os projetos educativos, mobiliza o inconsciente entre a criança e o adulto. Em certos momentos, o laço terapêutico revela sua dimensão de sedução, no sentido definido acima: o inconsciente, as pulsões de vida e de morte transmitem-se e circulam, 
como o fizeram, desde a origem, nos primeiros encontros entre os desejos do adulto e da criança. Duas formas de violência psíquica organizam-se a partir daí: a primeira, mortífera, alimenta as repetições inconscientes trabalhando no sintoma. Esta encontra algumas de suas raízes no sistema das relações familiares. A segunda, violência viva, separadora, é o fato do processo do tratamento: ela aposta nas forças de vida e induz ao conflito psíquico na criança.

Esses tempos solicitam o analista até no sentido de sua profissão: tratar de uma jovem paciente faz eco em si mesmo, à criança sofredora e viva que ele foi. Esta ponte estreita traz novamente para o adulto antigas questões e sua sublimação profissional: por que querer ser analista de crianças?

\section{REFERÊNCIAS BIBLIOGRÁFICAS}

Dolto, F. (1982). Sèminaire de psychoanalyse d'enfants, Seuil, Essais.

Ferenczi, S. (1932). Journal clinique (traduction équipe du Coq héron), Paris, Payot, 1985.

(1933). Confusion de langue entre les adultes et les enfants. Dans Psychanalyse 4, oeuvres complètes (traduction équipe du Coq Héron) (Vol. 4, pp. 125-35). Paris, Payot, 1982.

Freud, S. (1914). Pour introduire le narcissisme. Dans La vie sexuelle, (traduction, Laplanche, Berger) (pp. 81-105). Paris: PUF.
Klein, M. (1930). L'importance de la formation du symbole dans le développement du moi. Dans Essais de psychanalyse (traduction $\mathrm{M}$. Derrida) (pp. 263-78). Paris, Payot, 1968.

Lacan, J. (1962). L'angoisse. Document ronéotypé, Notes de cours.

----- (1969). Deux notes sur l'enfant. Ornicar, 37, 13-6.

Laplanche, J. (1971). Problématiques 1, l'angoisse. Paris, PUF.

-_-_(1989). Nouveaux fondements pour la psychanalyse. Paris, PUF.

Mannoni, M. (1967). L'enfant, sa "maladie" et les autes, Paris, Seuil.

Pechberty, B. (1985). Approuche clinique de la séparation en psychothérapie d'enfant. Le goupe familiar, 108, 21-4. (2000). L'infantile et la clinique de l'enfant. Paris, Dunod.

Tustin, F. ( 1986). Le trou noir de la psyché (traduction P. Chemla, trad.). Paris, Seuil, 1989.

Winnicott, D. (1958). Les formes cliniques du transfert. Dans De la pédiatrie à la psychanalyse (traduction de J. Kalmanovitch) (pp. 279-84). Paris, Payot, 1969. 